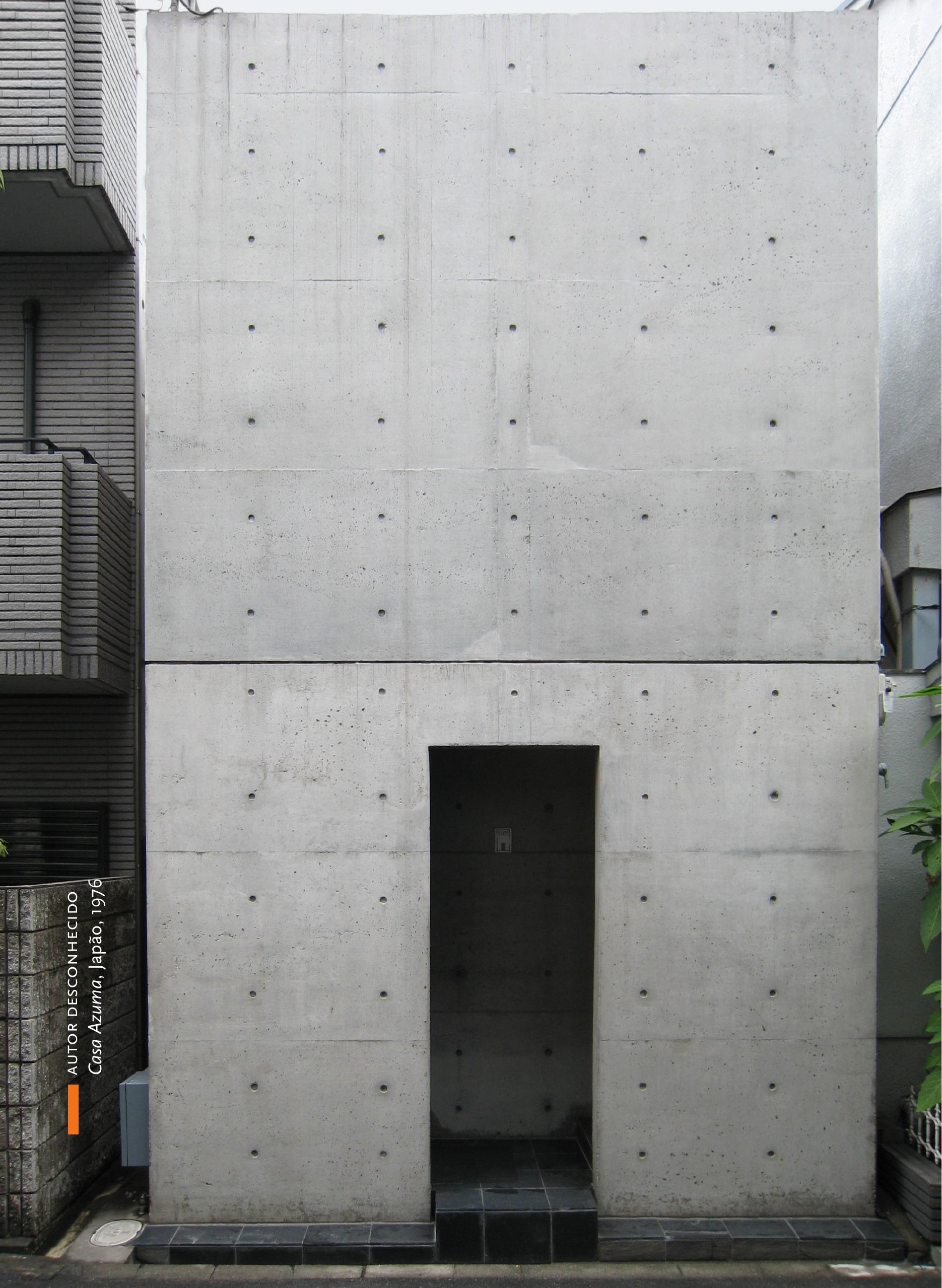




\section{TEMPO E PAISAGEM}

\section{ALTAMIRO SÉRGIO MOL BESSA*}

RESUMO Este ensaio trata da paisagem como espacialização do tempo, que, quando apreendido nos raros jardins que se insurgem no deserto paisagístico do mundo contemporâneo, pode trazer novas possibilidades ao pensamento. Dialogando com filósofos, historiadores da paisagem e artistas, descobre-se como as duas distintas gêneses da paisagem, a de tradição chinesa e a ocidental, tratavam a questão do tempo e do espaço. A primeira dava ênfase à paisagem como conciliação de opostos, um caminho a ser complementado pela imaginação, enquanto a segunda enfatizava os resultados. Tornada hoje hegemônica, a racionalidade ocidental coloca em campos distintos homem e natureza, tempo e espaço, configurando majoritariamente temporaneidades predatórias que se impõem violentamente sobre as lentas temporalidades que qualificam os lugares.

PalaVras-ChaVe Paisagem. Tempo. Jardim do tempo.

\section{TIME AND LANDSCAPE}

ABSTRACT This essay deals with the landscape as spatialization of time, which when apprehended in the rare gardens that occur in the scenic desert in contemporary world, may point out to new possibilities to the thought. Dialoguing with philosophers, landscape historians and artists, it shows how the two distinct landscape genesis, the Chinese and western traditions, treated the issue of time and space. The former puts its emphasis in landscape as reconciliation of opposites, a path to be complemented by imagination, where as the latter emphasizes the outcomes. Made hegemonic nowadays, the western rationality places in different fields man and nature, time and space, mostly setting predatory temporariness that violently imposes itself upon the slow temporality that qualifies the places.

KEYWORDS Landscape. Time. Garden of time.

* Professor Adjunto do Departamento de Urbanismo da Escola de Arquitetura da Universidade Federal de Minas Gerais. Doutor em Arquitetura e Urbanismo - USP - com pós-doutorado em Filosofia da Paisagem e Arquitetura Paisagística pela FAU-USP

E-mail: altamirobessa@gmail.com 


\section{Abertura}

odemos nos perguntar onde é possível apreender o tempo, observar sua passa-
gem. A paisagem, esta espacialização do tempo, é um lugar privilegiado para fazê-lo. Ela registra a narrativa temporal do pensamento humano, pelas marcas que faz aderir ao ambiente. A paisagem, esta categoria privilegiada enformadora do real, é o lugar onde tempo e espaço se articulam.

A passagem criativa do tempo habilita o espaço a ser paisagem. Sem isso, ela é apenas país, uma espécie de "espaço vacante”, para usar palavras de Carlos Drummond de Andrade. Para o poeta, a paisagem é um projeto que construímos com o tempo: "Paisagem, país / feito de pensamento da paisagem/ na criativa distância espacitempo" (ANDRADE, I973).

Alain Roger argumenta que, para operar a passagem do país `a paisagem, é necessária a operação da arte: "El país se queda en la indiferencia estética” (ROGER, 2006, p. 23). Essa artealização nasce, quando, confrontados com o lugar, o país "acorrenta-se ao nosso espírito", como diz Simmel (20I2), numa espécie de disposição anímica, chamada por ele de stimmung da paisagem, que faz reunir os elementos dispersos numa totalidade que nos toca. Segundo Berque (I994), essa disposição não está no ambiente, tampouco no sujeito, como se fosse um sonho ou alucinação, mas na trajetiva da interação entre um e outro.

Ainda em Berque (I994), a expressão do caráter estético que o homem estabelece com o seu ambiente revela a sensibilidade paisagística das civilizações. Essa sensibilidade pode expressar-se em duas formas de pensamento: o pensamento paisageiro (pensée paysagère), que evidencia que determinada cultura tinha uma relação estética com o meio, e um pensamento sobre a paisagem (pensée du paysage), que constitui uma reflexão crítica dessa relação. Para o autor, as primeiras civilizações na história da humanidade que apresentaram juntas esse par de formas de pensamento foram a chinesa, a partir do século IV, e a europeia, a partir do século XVI. 
A paisagem chinesa, como todo o seu pensamento, resulta de um longo e tumultuado processo cumulativo das noções e pressupostos do taoismo, confucionismo, budismo, entre outras escolas de pensamento. As contradições e diferenças entre eles evoluem de tal maneira que iam sendo acolhidas como alternativas ou complementaridade.

A ética predominante nessa tradição conciliadora atribui especial valor ao social e ao político, sem, contudo, retirar a importância do individual. O confucionismo, por exemplo, prescreve que o indivíduo se realiza em sociedade, enquanto que para o taoismo ele deve buscar uma harmonia com as forças da natureza. O jardim chinês acolhe as duas visões: ao mesmo tempo que é espaço de sociabilidade, também reserva lugares para a contemplação, a meditação e a introspecção solitária.

Na tradição chinesa, "o tempo não se apresenta como uma questão", pois ele "não aparece como intervalo entre um ponto de partida (a criação do mundo) e um ponto de chegada (o fim do mundo)" (TRIGOSO, 20II, p. 3). A construção paisagística chinesa buscava criar sequências de ambientes e visadas que surpreendessem os usuários, distorcendo-lhes a percepção espacial. Fracionando o lugar em diferentes ambientes, recusava a linearidade, visual e perceptiva, reservando a cada um deles seus próprios mistérios.

Outro importante aspecto que vale ressaltar é que o pensamento chinês está na realidade. Os chineses não estavam preocupados em alcançar o paraíso, mas em prestar atenção à natureza e às coisas. Nessa concepção, a ação humana não submete a natureza. Ao contrário, Lao-tsé, autor do livro considerado fundador do taoismo, o Tao Te Ching, prescrevia: “o Homem segue a Terra, a Terra segue o Céu, o Céu segue o TaO o Tao segue a Natureza".

Além de se revelarem como importantes alteridades que necessitam de um relativo afastamento dos cânones ocidentais para serem compreendidos, os pensamentos paisageiro e sobre a paisagem chineses tiveram fundamental importância nas culturas japonesa e ocidental.

No Ocidente, a paisagem surge da arte, no alvorecer da Modernidade, em que a ciência vai progressivamente afastando o homem da natureza, a ponto de classificar em campos distintos as ciências da natureza e as do espírito. A paisagem entra fazendo a mediação entre esse homem moderno e o mundo em que vive.

Agindo sobre e com o ambiente, o homem se afasta para contemplar suas ações, valorando-as objetiva e subjetivamente. A partir daí, determina as intervenções futuras, 
que terminam por atribuir ou retirar sentido dos lugares. A paisagem ocidental instaura-se, dessa forma, entre o fazer e o ver o que se faz, sendo não só o palco da ação, mas também sua representação.

O pensamento paisageiro ocidental envolve, então, ação e apreciação. Mais raro, no entanto, tem sido a ocorrência também de um pensamento sobre a paisagem, que acrescenta ao par anterior um terceiro termo: o juízo crítico. É especialmente esse pensamento crítico sobre as paisagens que faz avançar, como defende o paisagista americano Arnold Bearleant, no seminal Living in the Landscape. No mesmo sentido, Turri (20I3) enfatiza que as paisagens mais admiradas, reconhecidas pela sua qualidade estética e pela harmonia com a natureza são aquelas em que o homem-autor também se preocupou em posicionar-se como espectador e crítico dessa ação.

Rosário Assunto, em Il Paesaggio e l'estetica, argumenta que as paisagens são um espacializar-se do tempo, que ocorre por dois modos: pela temporalidade - a linha evolutiva qualificadora que conserva e traz o passado ao presente, prolongando-o ao futuro - e pela temporaneidade, como a que toma conta das metrópoles contemporâneas. Essa é a ação que se apodera destrutivamente da temporalidade, uma constante remoção que faz prevalecer as coisas que têm prazo de validade programado, dada a sua natureza especulativa. De sua ação avassaladora sobre o ambiente, escapam poucos enclaves com alguma qualidade, dos quais muitos são capturados pelo turismo de massa e outras indústrias que os consomem como mercadorias. Sobram alguns raros, que passo a denominar neste ensaio de jardins do tempo - recortes paisagísticos muito especiais, onde se identifica um claro compromisso de cuidado com o melhor de suas temporalidades constitutivas.

Apresento dois destes exemplares: a Casa Azuma, em Sumyoshi, Osaka, e o Mosteiro Nossa Senhora das Graças, em Belo Horizonte, obras singulares de duas tradições: o primeiro, da oriental; o segundo, da ocidental.

Antes de apresentá-los ao leitor, julgo necessário construir um breve panorama de cada uma dessas tradições. 


\section{$A$ alteridade chinesa}

A ideia de paisagem surge pela primeira vez na China, mais de mil anos antes do Ocidente. Enquanto a paisagem ocidental nasce da pintura, a chinesa é primeiro identificada na literatura, no ano de 353. Essa origem literária resultou em muitas expressões para designar paisagem, sendo a mais tradicional shanshui, que significa montanha-água.

As altas montanhas, para o pensamento taoista mais antigo, eram lugares sagrados, de onde se poderia contemplar não o panorama da Terra, "e sim a misteriosa essência imaterial de seu espírito" (SCHAMA, I996, p. 408). Já a água é a metáfora para o Wuwei, o pensamento taoista da não interferência. Flexível e aparentemente insignificante, a água, ligada ao feminino Yin, vai vencendo pacientemente a matéria Yang da montanha, seja desgastando-a lentamente, seja desviando-se de obstáculos para continuar seguindo seu curso, do alto, onde nasce, para os vales e o mar. O par montanhaágua expressa a conciliação de opostos que constituiu a noção de paisagem oriental.

Os sábios chineses deambulavam pela natureza para captar esses dois elementos paisagísticos, registrando suas percepções nas artes da poesia e pintura. Na pintura, representavam as cenas em rolos de seda, que se sucediam interrompidas por intervalos em branco, metaforicamente representando a água. Esses espaços de suspensão são a "alma da pintura na China", falou o Prêmio Nobel de Literatura japonês, Yasunari Kawabata, pois fazem expandir as cenas representadas até o apreciador, que pode percebê-las como continuidade do próprio corpo.

Inspirados nessas pinturas eram construídos os jardins chineses. Neles, diferentes ambientes eram interrompidos por estratégias paisagísticas como elevações, lagos, anteparos de alvenaria, pavilhões e percursos sinuosos, que tornavam complexas e distorciam propositalmente a fruição, fazendo do fruidor um atribuidor de sentidos, pelo exercício da imaginação.

Na tradição chinesa, não há indissociabilidade entre o tempo e o espaço: Ele "não aparece como uma duração monótona, constituída pela sucessão de momentos qualitativamente iguais, mas como um conjunto de diferentes eras, estações ou épocas" (TRIGOSO, 2006, p. 4). A construção de paisagens nessa tradição exigia dos chineses uma grande simbiose com a natureza. 
A cultura chinesa teve significativo impacto no desenvolvimento das artes no Japão, cujas contribuições foram sendo acrescidas às influências nativas do Xintoísmo, que professa e venera a divindade da natureza. Mais tarde, foram acrescidos os ensinamentos do budismo, vindo da China no ano de 552, especialmente da doutrina zen, que propunha alcançar a paz com mais simplicidade, sem excessos de preceitos e ritos. Ela ganhou grande capilaridade na população e presença nas artes, incluindo a paisagística (PAZINI, 20I3).

A estética paisagística dessa doutrina expressou-se principalmente por pequenos jardins projetados como mundos protegidos para o cultivo da serenidade e prática da meditação, lugar do exercício da ascese. Se antes os jardins eram construídos por nobres e aristocratas, agora tornavam-se tarefa de monges, que consideravam a tarefa de construí-los uma prática religiosa (PAZINI, 20I3).

O tema da cabana, recorrente na literatura do budismo, tem grande importância para o pensamento paisagístico oriental. É na rusticidade da cabana, com sua porosidade, que se convidam os elementos naturais a entrar, que o homem em sua solidão se abriga para refletir sobre uma das suas maiores fontes de sofrimento: a dificuldade de aceitar a impermanência. As rusticidade e porosidade da cabana, conceitualmente a transformam numa ruína: “construída por mãos humanas e integrando materiais toscos, é, pela inclusão e expressão dessa impermanência, mais real no sentido que não foi feita para desafiar a temporalidade [...]" (CARVALHO, 20II, p. 80).

No Japão, a cabana era o centro da cerimônia do chá, que influenciou notavelmente as artes japonesas, inclusive as paisagísticas e arquitetônicas. Descrita pelo já citado escritor Yasunari Kawabata como "um encontro de sentimentos", a cerimônia era realizada em espaços metodicamente projetados pelos Mestres do Chá, desde o jardim externo até os objetos colocados no seu interior. A cabana do chá é construída para induzir ao "gozo estético" no seu interior e está na origem da sukiya, a casa tradicional japonesa (OKAKURA, 2008).

A ideia de suspensão, intervalo, pausa ou vazio, que em japonês se designa pela expressão ma, está fortemente presente na tradição oriental. Trata-se de "um colapso, através de meios estéticos, do mundo objetivo, espacial, no mundo subjetivo, temporal" (CARVALHO, 20II, p. I57). Arquitetonicamente, materializa-se na abertura, no respiro, no pátio, na porta ou portão; no desenho urbano, em praças, largos e vazios que al- 
teram a densidade do tecido urbano, dissolvendo-o ou reconstituindo-o (CARVALHO, 20II). O ma não é um acaso, mas uma intenção espacial projetada para uma outra experiência sensorial.

Um dos mais importantes arquitetos da atualidade, o japonês Tadao Ando, no início da sua carreira, projetou a Casa Azuma. Implantada em meio a um tradicional bairro japonês em Sumyoshi, Osaka, em terreno retangular de 3,6m de frente e I2,6 $\mathrm{m}$ de profundidade, a casa, de apenas $64,7 \mathrm{~m}^{2}$, é constituída de dois blocos cúbicos de concreto aparente, um colocado à frente e outro ao fundo do terreno. No seu centro, o arquiteto instala um pátio descoberto.

Afirmando que "a casa serve ao propósito de abrigar, tanto física quanto espititualmente", Ando, em Azuma, utiliza importantes princípios do milenar pensamento paisagístico oriental.

A casa está numa rua de habitações tradicionais japonesas e instala-se ali como uma provocação, ou, como diz Ando, "uma interrogação" a um mundo que pouco tolera o diferente e a ousadia. Ao usar um material estranho ao lugar e à cultura arquitetônica tradicional japonesa, ele instala ali uma shanshui, pois a conciliação do duo montanha-água também é provocativa: não está esvaziada de tensão. Água e pedra estão sempre em disputa.

A fachada da casa tem uma única abertura, a porta, como na cabana da cerimônia do chá. Atravessá-la é também um ritual de passagem de um mundo exterior em direção a um ambiente protegido, construído para o abrigo das intimidades. Como a cabana, a casa parece recusar o mundo, para que ele não a invada, mas deixa aberta uma porosidade, o pátio. Nesse pátio instaura-se o princípio do ma, o hiato espacial que promove a articulação funcional, a ventilação e a iluminação dos ambientes que se voltam para ele, como nas casas tradicionais japonesas, que no seu interior são escuras. Sobre isso, diz o arquiteto: “Quando você se acomoda no interior de um aposento escuro e dali olha para o jardim, que é iluminado naturalmente, você começa a sentir a relação fundamental que existe entre luz e escuridão, a razão pela qual elas precisam uma da outra para se expressar" (ANDO e AUPING, 2003, p. 56).

A Casa Azuma é uma conversa do homem com a natureza. Tadao Ando afasta as soluções óbvias dos tetos verdes, jardins vegetados ou espelhos d'água e constrói esse diálogo recusando-se a cobrir o pátio. Ao fazer isso, ele traz a natureza para o cotidiano 
da casa. Não importa o clima ou a temperatura, se venta, chove ou esteja nevando, as pessoas devem sempre atravessá-lo como uma experiência natural. "Como tudo na arquitetura, trata-se de uma questão de equilíbrio entre procedimentos de afastar a pessoa da natureza e de convidar a natureza a entrar no espaço" (ANDO e AUPING, 2003, p. 52), afirma o arquiteto.

O concreto aparente é o material de todas as obras de Ando. Para ele, esse material tem mais de mil cores. A cor, diz, não está na sua superfície, mas deve ser alcançada da profundidade daquele material. A cor no concreto é sutil, quase monocromática, como são as das pinturas e dos jardins orientais. Alcançá-la é uma questão de perseverança, conhecimento e técnica: Tadao Ando dedica cuidado especial às concretagens, testando previamente inúmeras misturas até alcançar a cor e textura desejadas. E o concreto, “que é capaz de absorver e complementar a natureza”(ANDO e AUPING, 2003, p. 35), com o tempo vai ganhando outros tons, resultado da ação da passagem do tempo, que vai deixando nele os registros das impermanências.

Estão também presentes na obra as ideias de ordem e simplicidade, expressas na geometria da edificação, na clareza programática e dos fluxos, na ausência de ornamentos e simplicidade do mobiliário. Sobre isso, diz o arquiteto: “Eu, é claro, fui muito influenciado pela arquitetura japonesa tradicional. Ela me ensinou, sobretudo, que expressões universais aspiram à simplicidade" (ANDO e AUPING, 2003, p. 46).

A Casa Azuma, um jardim do tempo oriental, foi premiada, em I976, pela Associação de Arquitetos do Japão.

\section{A paisagem ocidental}

Historiadores da paisagem elegeram como marco do seu surgimento no ocidente a carta que Francesco Petrarca enviou ao dominicano Dionigi di San Sepolcro relatando sua subida ao monte Ventoux. Em 26 de abril de I336, o poeta italiano resolveu subir o monte em busca de alento para uma paixão não correspondida. Depois de muito esforço físico, já no alto, após exultar-se pela vista extraordinária que de lá divisou, Petrarca abre o Confissões de Santo Agostinho e lê esta passagem: “E os homens se maravilham com as altitudes das montanhas e as ondas imensas do mar e a vasta extensão dos rios e o circuito do oceano e a revolução dos astros, mas não atentam em si mesmos". O 
poeta entrega-se ao chamado de Agostinho, que o convence a abdicar dos apelos sedutores do mundo exterior em favor da salvação de sua alma.

Segundo Joachim Ritter, Petrarca, ao não reconhecer na vista do Ventoux a fonte de sua paz espiritual, expressa o nascimento da cisão irreparável entre homem e natureza, antecipando o par de concepções de natureza que se desenvolverá no Ocidente daí em diante: de um lado, a da ciência, "das leis universais que regem, como constantes mensuráveis, o comportamento dos fenômenos"; de outro, a da paisagem, "atraente, próxima e qualitativa, que se dá sensivelmente na experiência estética”, oferecendo-se “à contemplação de um observador que se encontra existencial e gnosiologicamente já fora dela" (SERRÃO, 20I3, p. I8).

Na passagem do mundo de Petrarca para a Modernidade, um conjunto de acontecimentos notáveis - como a emergência do pensamento humanista e a invenção da perspectiva, técnica que possibilitou trazer o exterior para o quadro, organizando-o segundo o olhar do artista - encontrarão, no norte da Europa do século XVI, especialmente pela sua laicização, as condições para a afirmação de uma nova forma artística de representar o mundo: a pintura de paisagem.

É essa pintura que vai fornecer os artifícios pelos quais o homem moderno passará a ver o seu lugar de vida. Utilizando a perspectiva, o pintor de paisagem enquadrava, como se fosse uma janela, a porção do exterior sob o seu ponto de vista. Essa janela também construía outra separação: um eu dentro e o mundo fora.

Assim, são o olhar perspectívico e o enquadramento estético que constituem ontologicamente a paisagem ocidental. O que faz uma porção do ambiente ou da natureza - este "nexo infindo das coisas", como diz Simmel (20I2) - ser uma totalidade compreensível, ou seja, a paisagem, é justamente o seu enquadramento por uma tomada de posição estética.

Esse novo modo de ver paisagístico vai ser disseminado primeiro entre as elites, os artistas, nobres e aristocratas europeus, em obras de arte, literárias, jardins, parques, palácios e cidades. O modelo preferido dessa artealização eram as pinturas clássicas, inspiradas nos princípios do pitoresco e da estética do sublime, especialmente na Inglaterra, que pretendia transformar-se numa "Nova Roma” (PAZINI, 20I3).

Essa estética paisagística vai popularizar-se por meio do Grand Tourist, viagens culturais à terra do classicismo, a Itália, que durou entre os séculos XVI e XIX. Praticado 
inicialmente por ricos, foi ganhando a adesão da classe média urbana e importantes intelectuais, como Rousseau e Goethe, que contribuíram para disseminar o hábito de viajar e caminhar como prática formativa e estética, mas foi Friedrich Nietzsche (I844-1900), também um filósofo deambulador, que ampliou a ideia de paisagem tomada como um lugar de fruição e contemplação do grandioso e do belo. As paisagens de Nietzche eram o campo para o aprofundamento do seu juízo crítico do mundo, especialmente em relação à sociedade, moral, religião e ciência. Ele constrói o seu pensamento na fórmula: caminhar, pensar, anotar e desenvolver os temas em casa. O filósofo dizia: “Não escrevo somente com a mão/ O pé também dá sua contribuição/ Firme, livre e valente ele vai/ Pelos campos e pela página (NIETZSCHE, 20I2, p. 43). E recomendava; "Agora ande, andarilho!".

Nietzsche andava pelos lugares subindo e descendo. O alto e a distância, para o filósofo, tinham uma grande força: “Gosto, como os animais da floresta e do mar, / De por algum tempo me perder, / De permanecer num amável recanto a cismar, / E enfim me chamar pela distância, / Seduzindo-me para - voltar a mim” (NIETZSCHE, 20I2, p. 32).

Mas o corpo imerso nas paisagens como forma de conhecimento do mundo começa a perder força com a invenção da máquina a vapor - que acelera o tempo das viagens e leva as pessoas a fazê-las confinadas em trens e navios, transformando o Grand Tourist em Mass Tourist - e com a aceleração dos efeitos das inovações tecnológicas e do capitalismo sobre os assentamentos humanos.

As antigas cidades medievais tiveram suas muralhas ultrapassadas pelo processo de dispersão urbana, centrado na lógica rentista da "planta em grade”, mais lucrativa, que não considerava as especificidades topográficas, históricas e socioespaciais locais. As distâncias intraurbanas ampliaram-se, e a mobilidade diária foi-se tornando penosa e desagradável.

Esse modelo de urbanização extensiva e desoladora foi-se disseminando pelas cidades ocidentais, provocando um grande apagamento das identidades dos lugares e da base material que durante séculos foram enformando suas paisagens. Atualmente é também adotado no Oriente, especialmente na China, implantando-se violentamente sobre uma cultura com outra tradição paisagística.

Para Bearleant (I997), as paisagens das metrópoles atuais deixaram para trás a matriz pictórica, substituindo-a pela arquitetônica, fundando o que denominou "esté- 
tica da continuidade”. Nessa estética, o ambiente urbano não é mais só aquilo que nos envolve, mas também o que nos penetra. E na maioria dos lugares o que nos penetra são degradação, violência, ruído inescapável do trânsito, poluição, odores químicos, a opressão sem graça dos edifícios, fios e antenas, outdoors e tantos outros produtores de danos diários que terminam por nos dessensibilizar.

Viver nessas cidades, especialmente em suas franjas urbanas, tem sido uma experiência ambiental de endurecimento, "esta espessura de pele que se torna progressivamente rígida, matéria dura como um couro sobre o qual a experiência desliza sem sensibilizar" (BESSE, 2006, p. I06). Isso vai reduzindo a nossa capacidade perceptiva e, consequentemente, nosso poder de imaginar, e, sem eles, onde faremos habitar o onírico, as utopias e a beleza?

Em Belo Horizonte, há um jardim do tempo em que podemos encontrá-los.

O mosteiro beneditino feminino Nossa Senhora das Graças implanta-se numa colina na Vila Paris. Nos anos iniciais de sua construção, na década de I950, a ocupação ali era rarefeita. O projeto, encomendado ao arquiteto modernista carioca Francisco Bolonha, era constituído de um edifício para cem religiosas, com jardins circundantes. Sua construção ocorreu em fases e durou 50 anos.

Quando a subida ao Mosteiro é feita a pé, como eu e meus alunos fizemos, à moda de Nietzsche, pode-se ter uma experiência especial de conhecimento e desvelamento, se houver disposição do andarilho para isso.

Já no percurso sinuoso da subida, vai-se atravessando várias paisagens - desde aquela que ainda traz predominantemente a confusão da cidade, até a mais silenciosa e reveladora dos sentidos, que ocorre no interior do Mosteiro.

Uma primeira tomada de posição paisagística realmente diferente ocorre quando já se consegue notar a mudança no tecido urbano e na tipologia arquitetônica, o decréscimo da temperatura, certa diminuição dos ruídos difusos da cidade, o adensamento da vegetação e o barulho das aves que começam a substituir o dos carros.

A subida vai sendo orientada pela torre sineira do Mosteiro, que anuncia um espacitempo diferente. Certa introspecção vai-se intensificando à medida que sabemos aproximar aquela paisagem do mundo religioso.

Aos poucos, o edifício do Mosteiro se mostra, às vezes oculto pelas grandes árvores do jardim que se foi consolidando no coroamento do morro ou por outras margeadas 
pelo muro circundante. Ultrapassado o portão de acesso, o mosteiro vai aparecer por inteiro logo depois de uma curva, apoiando-se suavemente no movimentado terreno sobre um entablamento de pedra. Apresentado, ele expõe toda a sua racionalidade modernista. O jogo de aberturas da fachada, a mudança na inclinação dos tetos e a verticalidade do campanário orientam o visitante, tornando legível e compreensível sua arquitetura, assim como a regra de São Bento, criada no século V, orienta toda a vida no seu interior.

A fachada do prédio lembra uma fábrica, e a Igreja diferencia-se pelo teto abruptamente inclinado que captura a luz exterior em direção ao altar. Todo o interior é solene, sóbrio e silencioso. Sobre a porta que separa os parlatórios do claustro principal, a inscrição Secundum Verbum anuncia uma intenção de ruptura com o tempo secular, instalando o do sagrado.

O claustro do Mosteiro é um jardim dentro daquele jardim do tempo. Reservado à intimidade, poucas vezes aberto a visitantes, é uma paisagem de grau máximo de proteção, que é fortemente invadida pelo céu (Fig. I), que nela ganha um imenso protagonismo. Com as nuvens, ele abraça aquela paisagem formando seu plano de cobertura protetor, rompido apenas pela grande torre de concreto aparente, de $25 \mathrm{~m}$ de altura, que aponta em sua direção, como a reforçar o vínculo de pertencimento daquele lugar

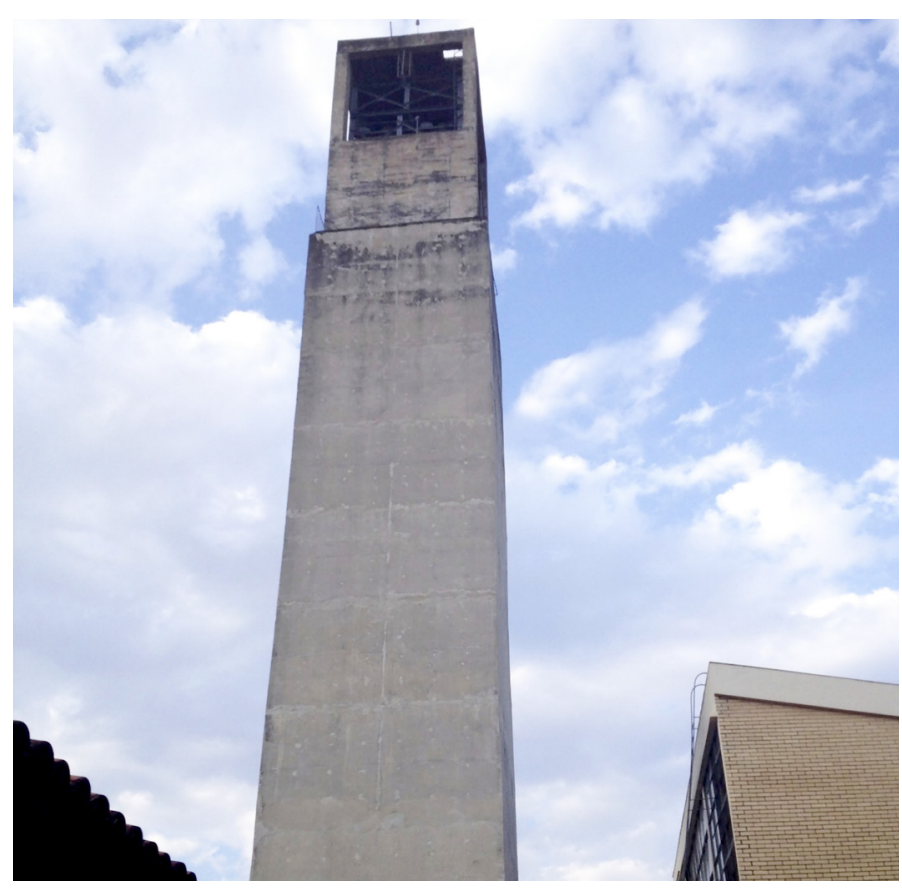

FIGURA 1 - Campanário do Mosteiro visto do claustro - Foto do autor, 2014 com a "Cidade Celestial", modelo que orienta a construção dos mosteiros desde o quinto século. O final da torre, já quase encontrando o céu, onde está a maquinaria dos sinos, pareceme uma grande boca aberta da qual imagino Santo Agostinho interpelando os "Petrarcas" que insistirem em buscar no mundo exterior a sua paz espiritual.

Essa mesma torre é a verticalidade necessária em toda paisagem, um movimento entre o lugar que se vive e o alto, que reposiciona e relativiza os nossos dramas humanos (lembremos que foi a visão da Terra do alto de Gagarin e sua narrativa que fizeram o mundo enxergarse como uma única casa). 
Abrigando uma comunidade cuja rotina diária é expressa por ordem, estabilidade e disciplina, a vida no Mosteiro é comandada pelas chamadas “Horas Canônicas”, uma divisão do tempo instituída no século XI e seguida pelos fiéis, por meio do chamado Livro das Horas², em que cada uma das horas corresponde a um ofício divino33.

Alguns desses ofícios são realizados em latim e com o canto gregoriano acompanhado da cítara, um instrumento antigo que poucos sabem executar. Quando se assiste a um deles, de corpo e alma, compreende-se melhor o que Berque quis dizer quando afirmou que a paisagem está na trajetiva entre as coisas e o sujeito que as percebe. Também se compreende melhor o porquê dos danos cotidianos serem tão nefastos à nossa experiência perceptiva: é preciso muita sensibilidade e concentração para "desendurecer" e apreciar a beleza daqueles momentos, naquele lugar, num tempo que não sabemos bem mais qual é.

Francisco Bolonha utilizou, com muita sensibilidade, o modernismo, uma vanguarda arquitetônica do século XX, para abrigar uma milenar tradição beneditina. Por sua vez, as pessoas que escolheram viver ali reconheceram nessa arquitetura um lugar digno para abrigar suas práticas religiosas e passaram a cuidar dele como se cuida de um jardim. O resultado é uma paisagem de extraordinária força simbólica que constitui expressão paisagística de uma temporalidade resistente frente a uma cidade que parece ter optado pela indiferença estética.

\section{Considerações conclusivas}

As paisagens são uma resposta do tempo e do pensamento às necessidades da vida nos lugares.

Como construção social, elas transformam-se com as mudanças nos valores das sociedades, mas isso deve acontecer permitindo que haja bons avanços coletivos. A valoração das paisagens apenas como algo a ser apreciado não é suficiente para que isso ocorra. Se assim fosse, os territórios turísticos ou aqueles protegidos pelas legislações de proteção do patrimônio seriam os melhores lugares de vida, o que necessariamente não é verdade. Por isso é preciso exercitar também um pensamento crítico sobre as paisagens.

A modernidade ocidental e sua razão, tornada hoje hegemônicas, representaram avanços significativos na ciência, mas trouxeram também certo empobrecimento da
2 As Riquíssimas Horas do Duque de Berry é um livro das horas do início do século XIV, encomendado pelo duque aos irmãos Limbourg. É considerado o primeiro trabalho ocidental em que a paisagem surge como autônoma na representação pictórica (ROGER, 2007).

3 Matinas, Prima, Terça, Sexta, Noa, Vésperas e Completas. 
apreciação paisagística, pelo nosso endurecimento, resultado de danos cotidianos impostos aos cidadãos nas metrópoles. Empobreceu também o pensamento crítico sobre as paisagens, seja pela diminuição de referentes qualitativamente estimulantes ou do exercício de avaliar e refletir sobre a nossa construção paisagística cotidiana. Essas são, na minha opinião, as principais razões do declínio qualitativo de grande parte das paisagens urbanas contemporâneas.

A paisagem, que nasceu da arte, foi afastando-se dela pela pressa desestabilizadora da urbanização de lucro fácil que vamos construindo no Ocidente, que está preocupada em transformá-la, o mais rápido possível, em uma mercadoria consumível. Esse modus operandi agora se impõe também aos lugares de rica tradiçäo paisagística conciliadora e aberta ao exercício da imaginação, como o Oriente, causando ali graves conflitos culturais e socioambientais.

No entanto, a arquitetura e o urbanismo, quando arte, podem ajudar a promover esse reencontro, construindo a base material dos jardins do tempo, como nos dois casos que foram relatados neste ensaio: a Casa Azuma e o Mosteiro Nossa Senhora das Graças.

Esses lugares especiais são a força resistente da temporalidade capaz de expor ao pensamento os bons princípios estruturadores da relação entre o homem, o tempo e o espaço na história das suas culturas constituintes. Ao mesmo tempo que recuperam o melhor de suas tradições, oferecem-se como estimulantes ao pensamento crítico. Ao fazerem isso, os jardins do tempo provocam, interrogam e desestabilizam, seja pela linguagem material ou formal inovadora, pelos usos incomuns que abrigam ou pelas relações inesperadas que constroem com o mundo circundante. São, igualmente, uma mensagem de otimismo!

Descobrir, apreciar, interpretar e cuidar dessas paisagens singulares e resistentes é forma não só de conhecimento e redescobertas, mas também de projetar um futuro. 


\section{Referências}

ANDRADE, Carlos Drummond. As impurezas do branco. Rio de Janeiro: José Olympio Editora, I973.

ANDO, Tadao; AUPING, Michael. Tadao Ando: conversas com Michael Auping. São Paulo: Editora G. Gili Ltda, 2003.

ASSUNTO, Rosário. Il paesaggio e l'estetica. Milano: Novecento, 2006.

BEARLEANT, Arnold. Living in the landscape. Toward an aesthetics of environment. Lawrence: University Press of Kansas, I997.

BERQUE, Augustin. Cinq propositions pour une théorie du paysage. Paris: Editions Champ Vallon, I994.

BESSE, Jean-Marc. Nas dobras do mundo. Paisagem e filosofia segundo Péguy. In: BESSE, Jean-Marc. Ver a Terra: seis ensaios sobre a paisagem e a geografia. Trad. Vladimir Bartalini. São Paulo: Perspectiva, 2006, p. 97-ıo6.

CARVALHO, Thiago Mesquita. Arte e natureza no budismo japonês. Lisboa, 20II, I62 f. Dissertação (Mestrado em Filosofia). Mestrado em Filosofia da Faculdade de Letras da Universidade de Lisboa, Lisboa, 20II.

NIETZSCHE, Friedrich. A Gaia Ciência. São Paulo: Companhia das Letras, 2012. OKAKURA, Kakuzo. O livro do chá. Trad. Leiko Gotoda. São Paulo: Editora Estação Liberdade Ltda, 2008.

PAZINI, Franco. Projetar a natureza. Arquitetura da paisagem e dos jardins desde as origens até a época contemporânea. São Paulo: Editora Senac, 2013.

ROGER, Alain. Breve tratado del paisaje. Madrid: Editorial Biblioteca Nueva, 2007.

SCHAMA, Simon. Paisagem e memória. São Paulo: Companhia das Letras, I996.

SIMMEL, Georg. A filosofia da paisagem. Trad.: Artur Morão. Covilhã: LusoSofia Press, 2009 .

SERRÃO, Adriana Veríssimo. Paisagem: Natureza Perdida, Natureza Reencontrada? Revista de Filosofia Moderna e Contemporânea, v.I, n.2, Lisboa, 2013.

TRIGOSO, Maria. A (não) questão do tempo na tradição chinesa. Cultura - Revista de História e Teoria das Ideias. Centro de História da Cultura, Universidade Nova de Lisboa, Lisboa, vol. 23.

TURRI, Eugênio. A paisagem como teatro. Do território do vivido ao território representado. In: SERRÃO, Adriana Veríssimo (Coord.). Filosofia da paisagem. Uma antologia. Lisboa: Centro de Filosofia da Universidade de Lisboa, 2013, p. I67 - I84. 